\title{
Oxygen Consumption by Phalaenopsis Plantlets and Chrysanthemum Cuttings as a Function of Temperature and Time: Model Structure Validation
}

\author{
Lieven Van de Vondel ${ }^{1} * \mathbb{D}^{D}$, Annelies Christiaens ${ }^{2}$, An Vermeulen ${ }^{1}$, Marie-Christine Van Labeke ${ }^{3}$, \\ Frank Devlieghere ${ }^{1}$ and Peter Ragaert ${ }^{1}$
}

1 Department of Food Technology, Safety and Health, Faculty of Bioscience Engineering, Ghent University (UGent), Coupure Links 653, 9000 Ghent, Belgium; A.Vermeulen@UGent.be (A.V.); Frank.Devlieghere@UGent.be (F.D.); Peter.Ragaert@UGent.be (P.R.)

2 PCS Ornamental Plant Research, Schaessestraat 18, 9070 Destelbergen, Belgium; Annelies.Christiaens@pcsierteelt.be

3 Department of Plants and Crops, Faculty of Bioscience Engineering, Ghent University (UGent), Coupure Links 653, 9000 Ghent, Belgium; MarieChristine.VanLabeke@UGent.be

* Correspondence: Lieven.VandeVondel@UGent.be; Tel.: +32-9-264-60-32

\section{check for} updates

Citation: Van de Vondel, L.; Christiaens, A.; Vermeulen, A.; Van Labeke, M.-C.; Devlieghere, F.; Ragaert, P. Oxygen Consumption by Phalaenopsis Plantlets and Chrysanthemum Cuttings as a Function of Temperature and Time: Model Structure Validation. Agronomy 2021, 11, 237. https:// doi.org/10.3390/agronomy11020237

Academic Editors: Shimon Meir and Sonia Philosoph-Hadas

Received: 9 December 2020

Accepted: 24 January 2021

Published: 28 January 2021

Publisher's Note: MDPI stays neutral with regard to jurisdictional claims in published maps and institutional affiliations.

Copyright: (c) 2021 by the authors. Licensee MDPI, Basel, Switzerland. This article is an open access article distributed under the terms and conditions of the Creative Commons Attribution (CC BY) license (https:// creativecommons.org/licenses/by/ $4.0 /)$.

\begin{abstract}
Phalaenopsis spp. and Chrysanthemum are ornamentals with an important economic value. Currently, quality loss during storage and transport of plantlets and cuttings is a limiting factor for spreading the workload, broadening the export range, and the use of slower but more environmentally friendly transport. In the agro-food sector, equilibrium modified atmosphere packaging has enhanced the shelf-life of minimally processed produce. The required properties for an equilibrium modified atmosphere packaging system can be estimated from the respiration rate of the packaged commodity under specified atmospheric composition and storage temperature. In this work, a model structure is validated to estimate the respiration rate as a function of oxygen concentration and temperature for Phalaenopsis and Chrysanthemum. The oxygen concentration as a function of time was monitored in a closed system for different storage temperatures. The models show a good fit to the data. The model coefficients were dependent on the plant species and characteristics. The resulting formulae can be used to estimate the oxygen consumption rate of the produce under a range of oxygen concentrations and a temperature range from $15^{\circ} \mathrm{C}$ to $32^{\circ} \mathrm{C}$ for Phalaenopsis and from $2{ }^{\circ} \mathrm{C}$ to $14{ }^{\circ} \mathrm{C}$ for Chrysanthemum. The oxygen concentrations for which the formulae are valid depend on the storage temperature and plant species. The models can be used to estimate a dynamic oxygen consumption rate profile during storage and transport.
\end{abstract}

Keywords: Chrysanthemum; oxygen concentration; oxygen consumption rate; Phalaenopsis; storage; temperature

\section{Introduction}

Phalaenopsis is a genus of orchid species native to Tropical and Subtropical Asia and North-Eastern Australia [1]. Optimization of in vitro propagation protocols in the late 20th century heralded the beginning of mass production [2]. Breeding further increased the ornamental value and nowadays many variations in flower color exist, as well as segments with multiple spikes leading to an abundance of flowers. The genus Phalaenopsis is currently the most important flowering pot plant traded by the Dutch auctions with a turnover of 460 million EUR in 2019 [3]. Chrysanthemum is a plant genus containing several species of ornamental importance. In the late 17th century, Asian Chrysanthemum species were imported into Europe via The Netherlands [4]. In retail, Chrysanthemum is sold as a cut flower or as a potted plant. When looking at the statistics of the sales of cut flowers on Floraholland, Chrysanthemum had the second-highest turnover (after Rosa) and was the third most sold plant in units (after Rosa and Tulipa) in 2019 [3]. 
Propagation and production sites are often relocated to areas far away from the consumer market [5]. After in vitro multiplication of Phalaenopsis and in vivo multiplication of Chrysanthemum in low-labor-cost countries with a more favorable production climate, the plantlets are transported back to Western Europe for hardening and rooting until these young plants are ready to be sold on the market [6]. Improved storage and transport conditions could enhance the shelf life of the plant materials, which would allow for the use of slower means of transport by water or longer storage at the companies and thus a better spread of work. The conditions during transport and storage will influence the speed of quality reduction of the plant materials due to spoilage by micro-organisms or carbohydrate starvation amongst others.

A lot of knowledge on transport and storage techniques of fresh produce is present in the agro-food sector, but research is rather scarce for floricultural crops. The temperature has been reported as the most important factor for storage of cut Gerbera [7] and cut roses [8] amongst others. However, during storage of mature bare-rooted Phalaenopsis equestris plants, Su et al. [9] found no negative effects of high-temperature abuse unless in combination with other stressors such as darkness or low relative humidity. This is in line with the findings by Hou et al. [6], who found that lower temperatures $\left(15^{\circ} \mathrm{C}\right.$ and $20^{\circ} \mathrm{C}$ ) had a positive effect on the quality of Phalaenopsis amabilis during dark storage. High temperatures within a biological relevant interval, will lead to an enhanced respiration rate that in turn will cause a faster deprivation of carbohydrate reserves. Sufficient levels of carbohydrates are positively correlated with final quality and the ability to regrow in the case of Phalaenopsis [6]. For Chrysanthemum cuttings, no clear correlation was found between the amount of soluble carbohydrates and the capacity to form adventitious roots after storage. However, the adventitious rooting of cuttings was found to be positively correlated with the sucrose:starch ratio [10].

It is generally known that the respiration rate of plants or plant parts are influenced by both temperature and the composition of the atmosphere, which surrounds the plant materials. Modified atmosphere storage techniques are widely used to preserve minimally processed fruits and vegetables [11] which is based on reducing the respiration rate of the produce by reducing the $\mathrm{O}_{2}$ level often in combination with an increase in $\mathrm{CO}_{2}$ in the atmosphere. The headspace composition of modified atmosphere packages will change depending on the respiration rate of the product inside and the permeability of the package for $\mathrm{O}_{2}$ and $\mathrm{CO}_{2}$. Eventually, both respiration and permeability will be in equilibrium at a certain gas composition in the headspace and at a certain storage temperature. This type of modified atmosphere, in which the respiration rate of the produce and the permeability of the package are in equilibrium is called Equilibrium Modified Atmosphere Packaging (EMAP) [12,13]. The desired final gas composition depends on the packaged produce [14].

This research aims to validate the applicability of a model structure that has been used in the agro-food sector to estimate the required properties of a custom-made EMA package for long transport and storage times of Phalaenopsis in vitro plantlets ready for acclimation and unrooted Chrysanthemum cuttings. The model will predict the oxygen consumption rate $(O C R)$ as a function of $\mathrm{O}_{2}$ concentration and temperature. The validated model structure can then in a further step be used to calculate necessary EMAP configurations to increase the shelf-life of both species as the OCR of the plant material at a certain oxygen level and a temperature will be indicative to the required oxygen transmission rate of the package at that certain temperature [15].

\section{Materials and Methods}

\subsection{Optimization of Experimental Design}

Prior to the main experiments, the effect of the mass on the respiration rate was studied. To this end, Chrysanthemum cuttings (cv. A) were packaged $(2.5,5.0,7.5$, or $10 \mathrm{~g})$ in four hermetically sealed bottles per mass. The headspace of each empty respiration bottle + lid was determined gravimetrically and had a volume of $\pm 660 \mathrm{~mL}$. The bottles were closed under ambient air conditions and stored at $\pm 4{ }^{\circ} \mathrm{C}$ in June 2019. In November 2019, 
Phalaenopsis plantlets (clone 1834) were packaged $(25,50,75$, or $100 \mathrm{~g}$ ) in four repeats per mass. The bottles were hermetically closed under ambient air conditions and stored at $\pm 22{ }^{\circ} \mathrm{C}$. The mass for which the $\mathrm{O}_{2}$ concentration decreased from $10 \%$ to $1 \%$ within five days was roughly estimated from the data to define the mass which should be used in the main experiment. This mass was expected to be enough to ensure that the experiment would not take too long to avoid aging effects and to ensure that the mass was not too high to take enough measurements before the oxygen concentration reached $1 \%$. In the case of Chrysanthemum, extrapolation of the results was needed since $10 \mathrm{~g}$ was not enough to fulfill the requirements mentioned above.

Storage temperatures were chosen based on temperature loggings from different commercial transports (Figure S1).

\subsection{Experimental Design}

Plant materials (70 g Phalaenopsis plantlets in February, $65 \mathrm{~g}$ Phalaenopsis plantlets in March, and $30 \mathrm{~g}$ Chrysanthemum (cv. B and cv. C) cuttings) were packed in airtight bottles $( \pm 660 \mathrm{~mL})$. The atmospheric composition was actively modified during packaging and consisted of $10 \% \mathrm{O}_{2}+$ rest $\mathrm{N}_{2}$ and stored at five different temperatures. Per temperature, four bottles were stored. The temperature was logged and the $\mathrm{O}_{2}$ concentration was measured repeatedly for each bottle. Based on the measured $\mathrm{O}_{2}$ concentration as a function of time and based on the mean temperature in each storage room, model parameters were estimated. The derivate of the model allowed to calculate the OCR for a certain temperature and a certain oxygen concentration. Before packaging, the starch and soluble carbohydrate content, fresh weight, and dry weight were measured.

\subsubsection{Plant Materials}

In vitro Phalaenopsis plantlets (clone 1834) were provided by Microflor, Lochristi, Belgium. Plantlets had three to five roots and leaves when they were transported in their culture vessels to Ghent University, Belgium within $30 \mathrm{~min}$. The experiment was performed twice (February 2020 and March 2020). The plantlets obtained in February had been growing for six weeks in the last subculture. The plantlets in March were obtained after four weeks in the last subculture. The longer culture time in February was due to a commercial decision of Microflor. Plantlets were removed from the culture vessels, rinsed with tap water, and gently dried. Chrysanthemum cv. B (CB) and cv. C (CC) cuttings were freshly harvested at the PCS Ornamental Plant Research, Destelbergen, Belgium. The experiment with CB started in May 2020 and the experiment with CC started in June 2020. The experiments on Chrysanthemum were not repeated. The growth conditions of the mother plants were followed for $14 \mathrm{~d}$ before harvesting the cutting (Table 1). Cuttings were wrapped in a moist paper towel and plastic foil right after harvest and transported in cooling boxes within $30 \mathrm{~min}$ to Ghent University.

Table 1. Growth-chamber settings (day temperature, night temperature, relative humidity (RH) and daily light integral (DLI)) for in vitro plantlets Phalaenopsis (6 weeks after the last subculture for February and 4 weeks after the last subculture for March) and average growth conditions (day temperature, night temperature, relative humidity (RH) and daily light integral (DLI)) for stock plants of Chrysanthemum (cv. B from 11 May 2020 until 24 May 2020; cv. C from 8 June 2020 until 21 June 2020), shown as mean \pm SD.

\begin{tabular}{|c|c|c|c|c|}
\hline \multirow{2}{*}{ Plant Material } & \multicolumn{4}{|c|}{ Settings of Growth-Chamber } \\
\hline & Night Temperature $\left({ }^{\circ} \mathrm{C}\right)$ & Day Temperature $\left({ }^{\circ} \mathrm{C}\right)$ & RH (\%) & DLI (mol m-2 $\left.\mathrm{d}^{-1}\right)$ \\
\hline \multirow[t]{3}{*}{ Phalaenopsis (Feb/Mar) } & 23 & 25 & 50 & 1.3 \\
\hline & \multicolumn{4}{|c|}{ Average Growth Conditions } \\
\hline & Night temperature $\left({ }^{\circ} \mathrm{C}\right)$ & Day Temperature $\left({ }^{\circ} \mathrm{C}\right)$ & RH (\%) & $\operatorname{DLI}\left(\mathrm{mol} \mathrm{m}^{-2} \mathrm{~d}^{-1}\right)$ \\
\hline Chrysanthemum cv. B & $18.3 \pm 1.6$ & $23.9 \pm 1.3$ & $59.0 \pm 3.3$ & $13.6 \pm 6.8$ \\
\hline Chrysanthemum cv. C & $20.1 \pm 0.8$ & $24.0 \pm 0.7$ & $68.6 \pm 2.2$ & $14.2 \pm 7.3$ \\
\hline
\end{tabular}


Both starch and soluble sugars were determined for four groups of five random sampled plantlets (Phalaenopsis) or three groups of six random sampled cuttings (Chrysanthemum). Per group of Phalaenopsis plantlets, the second youngest leaf and the second youngest root were ground in liquid nitrogen with a mill (IKA ${ }^{\circledR}$ A11 Basic Analytical Mill, Staufen, Germany) at \pm 11:00. For CC and CB, stems and leaves were separated and ground in liquid nitrogen with pestle and mortar $5.5 \mathrm{~h}$ after sunrise. The visible meristems were removed from the stems and the stems were cut in small discs with a scalpel. The ground materials were stored at $-80{ }^{\circ} \mathrm{C}$ until analyzed.

Carbohydrates were extracted in $80 \%$ ethanol at $45^{\circ} \mathrm{C}$ for $3 \mathrm{~h}$, followed by centrifugation at $5000 \times g$ for $5 \mathrm{~min}$ (Centrifuge $5804 \mathrm{R}$, Eppendorf, Hamburg, Germany). The soluble carbohydrates were quantified by high-pressure liquid chromatography with pulsed amperometric detection (ACQUITY UPLC H-Class, Waters, Milford, MA, USA). Myo-inositol, glucose, fructose, and sucrose were separated with a CarboPac MA1 analytical column and companion guard column (Thermo Fisher Scientific, Sunnyvale, CA, USA) and an eluent of $500 \mathrm{mM} \mathrm{NaOH}$ at $30{ }^{\circ} \mathrm{C}$ for Phalaenopsis. Sucrose, glucose, fructose, raffinose, and stachyose were separated with a CarboPac PA-20 analytical column and companion guard column (Thermo Fisher Scientific, Sunnyvale, CA, USA) and an eluent of $50 \mathrm{mM} \mathrm{NaOH}$ at $35^{\circ} \mathrm{C}$ for Chrysanthemum.

The remaining pellet was washed twice with ethanol $80 \%$ and treated with $1 \mathrm{M} \mathrm{HCl}$ for $2 \mathrm{~h}$ at $95^{\circ} \mathrm{C}$ for starch hydrolysis. Starch was determined spectrophotometrically at $340 \mathrm{~nm}$ by the enzymatic reduction of NADP ${ }^{+}$(UVVIS, Biotek Uvikon XL, Bad Friedrichshall, Germany) [16].

\subsubsection{Storage Conditions}

Five different storage temperatures were chosen per plant species. For Chrysanthemum, no temperatures above $15^{\circ} \mathrm{C}$ were used because the respiration rate at these higher temperatures is too high to be monitored accurately. The temperature was logged each $10 \mathrm{~min}$ with IButton data loggers 1922T\#F50 (Mouser, The Netherlands) which were inserted in two bottles per temperature. The resolution of the data loggers was set to $0.5^{\circ} \mathrm{C}$ (Table 2).

Table 2. Storage temperatures during experiments, shown as mean \pm SD.

\begin{tabular}{cccccc}
\hline \multirow{2}{*}{ Plant Material } & \multicolumn{5}{c}{ Storage Temperatures $\left({ }^{\circ} \mathbf{C}\right)$} \\
\cline { 2 - 6 } & T1 & T2 & T3 & T4 & T5 \\
\hline Phalaenopsis (Feb) & $15.5 \pm 0.5$ & $18.9 \pm 0.5$ & $22.8 \pm 0.5$ & $27.0 \pm 0.7$ & $32.6 \pm 1.1$ \\
Phalaenopsis (Mar) & $15.5 \pm 0.2$ & $18.9 \pm 0.6$ & $22.3 \pm 0.7$ & $27.2 \pm 0.9$ & $32.3 \pm 1.0$ \\
Chrysanthemum cv. B & $2.1 \pm 0.7$ & $5.2 \pm 0.6$ & $7.4 \pm 0.6$ & $9.9 \pm 0.5$ & $14.4 \pm 0.4$ \\
Chrysanthemum cv. C & $1.7 \pm 0.9$ & $4.5 \pm 0.6$ & $7.5 \pm 0.8$ & $10.3 \pm 0.6$ & $14.5 \pm 0.4$ \\
\hline
\end{tabular}

\subsubsection{Packaging}

Phalaenopsis plantlets were put in aluminum wrapped glass bottles $( \pm 660 \mathrm{~mL})$ immediately after harvest. The filled (but not yet closed) bottles were put at the different storage temperatures, 2 to $3 \mathrm{~h}$ preceding the actual packaging step to allow acclimatization. In the case of both Chrysanthemum cv's, the plant material was randomly divided into five groups. Each group was temporarily wrapped in plastic foil and stored for $2 \mathrm{~h}$ preceding the packaging at one of the storage temperatures to allow acclimatization.

After two to three hours of adaptation to the storage temperature, the bottles (Phalaenopsis) or packages (Chrysanthemum) with the plants were transported in an insulated box to the packaging hall to introduce a modified atmosphere in the bottles. Thirty-gram Chrysanthemum cuttings were put in the bottles $( \pm 660 \mathrm{~mL})$ right before packaging. The hermetic seal between bottles and lids was insured by the incorporation of petrol jelly (VWR, Belgium). The bottles with their corresponding lids were packaged in high barrier bags (PA/PE/EVOH/PE, $80 \mu \mathrm{m}$, EuralPack, Belgium). Using a Multivac C300 vacuum packaging machine (Multivac, Mechelen, Belgium) connected to a Witt MG18-3MSO gas 
mixer (Gasetechnik, Germany), the bags with the bottles were filled with a gas mixture of $9.8 \pm 0.1 \% \mathrm{O}_{2}+$ rest $\mathrm{N}_{2}$ and sealed. Before opening the bags, the bottles were closed with the corresponding lids. The lids were equipped with a rubber septum to allow for sampling the headspace. The bottles with Phalaenopsis were closed right after sealing. The bottles with $\mathrm{CB}$ and CC were closed after two extra hours of storage in the bags to avoid low headspace pressure due to the low storage temperature. Right after closing the bottles, the headspace composition of the bag was measured with a Checkpoint $\mathrm{O}_{2}+\mathrm{CO}_{2}$ measuring device (PBI Dansensor, Belgium). To this end, a septum was stuck to the bag and the septum was pierced with a needle, connected to the Checkpoint. Then, the closed bottles were taken out of the bags. The closed bottles were stored back at the same temperature as before packaging.

\subsubsection{Measurement of Headspace Composition}

The oxygen levels in the headspace of the hermetically sealed jars were measured repeatedly with a Checkmate 3 (Mocon Dansensor, Denmark), equipped with a Zr-sensor for oxygen measurement and an infrared sensor for carbon dioxide measurement. Three milliliters of gas was used for each analysis until the oxygen level dropped below $2 \%$. When the oxygen level was lower than $2 \%, 6 \mathrm{~mL}$ gas was sampled and below $1 \%$ oxygen, $9 \mathrm{~mL}$ gas was sampled. A larger sample volume at lower oxygen concentrations was needed to avoid erroneous measurements due to air residues in the sampling tube and gas analyzer.

The $\mathrm{CO}_{2}$ concentration was measured two times for each bottle. The first time, the $\mathrm{CO}_{2}$ concentration of all bottles was measured when the $\mathrm{O}_{2}$ concentration in the bottles stored at the highest temperature, reached an $\mathrm{O}_{2}$ concentration of $1 \%$. The second $\mathrm{CO}_{2}$ measurement took place for the vessels at each temperature separately when the headspace of the vessels stored at that specific temperature reached an $\mathrm{O}_{2}$ concentration of $1 \%$. To measure both $\mathrm{O}_{2}$ concentration and $\mathrm{CO}_{2}$ concentration, $10 \mathrm{~mL}$ gas was withdrawn from the headspace.

Immediately after measuring both $\mathrm{CO}_{2}$ concentration and $\mathrm{O}_{2}$ concentration with the Checkmate, the headspace of the bottle was also sampled ( $5 \mathrm{~mL}$ with an airtight syringe) to determine the ethylene concentration with a gas-chromatograph (Thermofisher Trace 3000) equipped with a thermal conductivity detector (TCD) for measurement of oxygen and carbon dioxide, and a flame ionization detector (FID) to quantify ethylene. The flow rate was set to $35 \mathrm{~mL} \mathrm{~min}^{-1}$. The FID temperature was set to $250{ }^{\circ} \mathrm{C}$. For the measurements with the TCD, the reference flow rate (He-gas) was set to $1 \mathrm{~mL} \mathrm{~min}^{-1}$, and the temperature of the detector was set to $110{ }^{\circ} \mathrm{C}$. When the $\mathrm{O}_{2}$ concentration and $\mathrm{CO}_{2}$ concentration measured with the Checkmate differed more than an absolute concentration of $0.5 \%$ from the respective concentrations measured with the GC, the measured ethylene was considered unreliable and was discarded. This was carried out because the sampling and injection of the samples in the GC comes with a high risk of contamination with ambient air.

\subsection{Data Analysis}

\subsubsection{Modeling of the Respiration Rate}

The $\mathrm{O}_{2}$ concentration was modeled as a function of time $(t)$ using Equation (1) [12,17]. According to Jacxsens et al. [18], an Arrhenius equation can be used to express the relation between OCR and the temperature $(T)$ (in $K$ ). We propose to incorporate the effect of the temperature on the coefficients " $a$ " and " $b$ " of the quadratic model using Equation (2). The different hermetically sealed bottles are incorporated as random effects (Equation (3)) to account for random differences between the bottles.

$$
\left[\mathrm{O}_{2}\right]_{t}=a \times t^{2}-b \times t+c
$$


With: $\left[\mathrm{O}_{2}\right]_{\mathrm{t}}$ is the oxygen concentration (in volume\%) at time $t$ and $t$ is the time (in hours). $a, b$ and $c$ are model coefficients.

$$
\ln (\text { coef })=\beta_{\text {coef }, 1}-\beta_{\text {coef }, 0} /(R \times T)
$$

With: $\ln$ (coef) is the natural logarithm of coefficient $a$ or $b, \mathrm{R}$ is the universal gas constant $\left(8.314463 \mathrm{~m}^{3} \mathrm{~Pa} \mathrm{~K}^{-1} \mathrm{~mol}^{-1}\right.$ ) and $T$ is the temperature (in K). $\beta_{\text {coef }, 1}$ and $\beta_{c o e f, 0}$ are the model coefficients for the fixed effects.

$$
a+b+c \sim 1 \mid b o t t l e
$$

With: $a, b$, and $c$ as coefficients from Equation (1). The bottle in which the plant materials are packaged is used as the grouping factor.

The respiration rate was calculated from the oxygen consumption by the plant materials according to Equation (4) and thus, is expressed as the oxygen consumption rate (OCR) per kg of plant materials per hour $\left(\mathrm{mL} \mathrm{kg}^{-1} \mathrm{~h}^{-1}\right)$.

$$
O C R=\frac{-d[O 2]}{d t} \times V /(100 \times m)
$$

With: the oxygen consumption rate (OCR) expressed in volume of oxygen (in $\mathrm{mL}$ ) consumed per time (in h) per mass of produce (in $\mathrm{kg}$ ); the volume $(V)$ is the headspace volume in $\mathrm{mL}$ (= volume of the empty bottle minus the volume of the plantlets); the mass $(m)$ in kg plant materials; $\mathrm{O}_{2}$ concentration $\left[\mathrm{O}_{2}\right]$ is the oxygen concentration in volume percent and $t$ is the time in hours between the closing of the bottle and the measurement. To estimate the volume of the headspace V, prior to the experiments, the density of Phalaenopsisplantlets and Chrysanthemum cuttings were determined and found to be approximately $1 \mathrm{~g} \mathrm{~mL}^{-1}$ and $0.88 \mathrm{~g} \mathrm{~mL}^{-1}$ respectively (data not shown).

Out of Equations (1) and (4), follows Equation (5), which expresses the OCR as a function of time.

$$
O C R=-(2 \times a \times t-b) \times V /(100 \times m)
$$

To allow the estimation of the $O C R$ as a function of oxygen concentration, Equation (1) should be rearranged to express the time $t$ as a function of oxygen concentration $\left[\mathrm{O}_{2}\right]_{\mathrm{t}}$ for the interval in which $\left[\mathrm{O}_{2}\right]_{\mathrm{t}}$ declines as a function of the time. Next, the time $t$ in Equation (5) was substituted by this rearranged equation. The substitution resulted after simplification in Equation (6), which expresses the $O C R$ as a function of $\mathrm{O}_{2}$ concentration:

$$
\text { OCR }=V /(100 \times m) \sqrt{b^{2}-4 \times a \times\left(c-\left[O_{2}\right]\right)}
$$

To take the effect of the temperature into account, the estimated fixed effect of the temperature on the coefficients $\mathrm{a}$ and $\mathrm{b}$ can be included in Equation (6), which results in Equation (7).

$$
O C R=V /(100 \times m) \sqrt{\exp \left[\beta_{b, 1}-\beta_{b, 0} /(R \times T)\right]^{2}-4 \exp \left[\beta_{a, 1}-\beta_{a, 0} /(R \times T)\right]\left(c-\left[O_{2}\right]\right)}
$$

The model was built in RStudio [19], extended with the nlme package [20] for nonlinear mixed-effects modeling.

\subsubsection{Model Evaluation}

To evaluate the nonlinear mixed effect models based on Equation (1) to Equation (3), visual methods were used. The observed $\mathrm{O}_{2}$ concentration was plotted as a function of the time together with the modeled decrease in the $\mathrm{O}_{2}$ concentration as a function of the time per storage temperature. Next, the predicted $\mathrm{O}_{2}$ concentration was plotted as a function of the observed $\mathrm{O}_{2}$ concentration for each observation. The predicted $\mathrm{O}_{2}$ concentration in both figures was calculated from the fixed effects. 


\subsubsection{Ethylene and Carbohydrate Levels}

The mean carbohydrate content between two tissues during the same experiment and the ethylene concentration between two measurement moments within one storage temperature were compared with paired two-sample $t$-tests when the normality assumption (based on a Shapiro-Wilk test) was accepted on a 0.05 significance level. In the other case, a Wilcoxon signed-rank test was used as a nonparametric alternative. A correction for inequality of variance was applied when a Levene's test indicated an inequality of variances based on the 0.05 significance level. Ethylene levels during the first measurement were compared between the different storage temperatures based on a one-way ANOVA when the normality assumption and the homoscedasticity assumption were both met. Else, a Kruskal-Wallis test was used as a non-parametric alternative. Statistical analysis was conducted in RStudio, extended with the carData and Car packages for regression and distribution tests [21,22].

\section{Results}

\subsection{Carbohydrate Content}

The carbohydrate contents of the leaves and roots of Phalaenopsis are shown in Table 3. In all cases, the roots have significantly higher hexose content (February: $p=0.03$; March: $p=0.03$ ) and sucrose content (February: $p=0.02$, March: $p<0.01$ ) compared to the leaves. The leaf hexose content was significantly higher in March $(p<0.01)$. There was no significant difference in myo-inositol content, nor in starch content between roots and leaves within February nor March (all $p$-values $>0.25$ ). The starch content in roots nor leaves was significantly different between both experiments (both $p$-values $>0.35$ ).

Table 3. Carbohydrate concentration in pooled samples of Phalaenopsis plantlets. Data are mean \pm SD $(n=4)$.

\begin{tabular}{|c|c|c|c|c|c|c|c|c|}
\hline \multirow{3}{*}{ Phalaenopsis } & \multicolumn{8}{|c|}{ Carbohydrate Concentration (mg g ${ }^{-1}$ FW) } \\
\hline & \multicolumn{2}{|c|}{ Myo-Inositol } & \multicolumn{2}{|c|}{ Hexoses } & \multicolumn{2}{|c|}{ Sucrose } & \multicolumn{2}{|c|}{ Starch } \\
\hline & Leaf & Root & Leaf & Root & Leaf & Root & Leaf & Root \\
\hline February & $0.15 \pm 0.02$ & $0.13 \pm 0.01$ & $1.97 \pm 0.95^{\mathrm{t}, \mathrm{e}}$ & $7.74 \pm 2.03^{t}$ & $0.61 \pm 0.20^{\mathrm{t}}$ & $2.00 \pm 0.46^{\mathrm{t}}$ & $0.68 \pm 0.30$ & $0.73 \pm 0.13$ \\
\hline March & $0.13 \pm 0.02$ & $0.12 \pm 0.01$ & $4.91 \pm 0.59^{\mathrm{t}, \mathrm{e}}$ & $7.18 \pm 0.70^{\mathrm{t}}$ & $0.63 \pm 0.06^{\mathrm{t}}$ & $2.31 \pm 0.21^{\mathrm{t}}$ & $0.79 \pm 0.10$ & $0.81 \pm 0.22$ \\
\hline
\end{tabular}

${ }^{\mathrm{t}}$ Significant difference between root and leave within the same experiment (paired $t$-test). ${ }^{\mathrm{e}}$ Significant difference between experiments within the same tissue (two-sample $t$-test), based on a 0.05 significance level.

The carbohydrate content of Chrysanthemum is included in Table 4. There was no stachyose found in most samples. In one of the leaf samples of $\mathrm{CB}$, there was no raffinose found and was, therefore, assumed 0.00. Compared to $C B, C C$ had a significant higher leaf hexose content $(p<0.01)$, a lower stem sucrose content $(p=0.02)$ and a lower stem raffinose content $(p=0.03)$. When comparing stems and leaves, the sucrose content was higher in the stems for $\mathrm{CB}(p=0.02)$, but lower in the stems of CC $(p=0.01)$. Leaf starch content was significantly higher compared to the stem starch content for $\mathrm{CB}(p=0.03)$, but not for CC $(p=0.1)$.

Table 4. Carbohydrate contents in pooled samples of Chrysanthemum plantlets cv. B and cv. C. Data are mean \pm SD $(n=3)$.

\begin{tabular}{|c|c|c|c|c|c|c|c|c|}
\hline \multirow{3}{*}{$\begin{array}{l}\text { Chrysanthemum } \\
\text { Cultivar }\end{array}$} & \multicolumn{8}{|c|}{ Carbohydrate Concentration $\left(\mathrm{mg} \mathrm{g}^{-1} \mathrm{FW}\right)$} \\
\hline & \multicolumn{2}{|c|}{ Hexoses } & \multicolumn{2}{|c|}{ Sucrose } & \multicolumn{2}{|c|}{ Raffinose } & \multicolumn{2}{|c|}{ Starch } \\
\hline & Leaf & Stem & Leaf & Stem & Leaf & Stem & Leaf & Stem \\
\hline cv. B & $0.80 \pm 0.05^{\mathrm{e}}$ & $0.79 \pm 0.13$ & $0.32 \pm 0.23^{t}$ & $0.59 \pm 0.25^{\mathrm{t}, \mathrm{e}}$ & $0.01 \pm 0.02$ & $0.04 \pm 0.01^{\mathrm{e}}$ & $5.5 \pm 1.3$ & $1.0 \pm 0.1$ \\
\hline cv. C & $1.70 \pm 0.28^{\mathrm{e}}$ & $1.62 \pm 0.51$ & $0.05 \pm 0.01^{\mathrm{t}}$ & $0.01 \pm 0.01^{\mathrm{t}, \mathrm{e}}$ & $0.04 \pm 0.01$ & $0.02 \pm 0.01^{\mathrm{e}}$ & $10.7 \pm 3.3^{\mathrm{t}}$ & $2.4 \pm 0.5^{\mathrm{t}}$ \\
\hline
\end{tabular}

${ }^{\mathrm{t}}$ Significant difference between root and leave within the same experiment (paired $t$-test). ${ }^{\mathrm{e}}$ Significant difference between experiments within the same tissue (two-sample $t$-test), based on a 0.05 significance level. 


\subsection{Ethylene Production}

Phalaenopsis plantlets produced small amounts of ethylene during storage (from $100 \mathrm{pmol} \mathrm{mol}^{-1}$ up to $350 \mathrm{pmol} \mathrm{mol}^{-1}$ ). No significant increase in ethylene could be found as a function of time. However, a slightly increasing trend was visible. Ethylene concentration was not affected by the temperature in February $(p=0.34)$ and March $(p=0.13)$.

Chrysanthemum cuttings produced higher amounts of ethylene compared to Phalaenopsis plantlets and here the ethylene production was higher by CB than by CC (Table 5).

Table 5. Effect of temperature on the ethylene production of Chrysanthemum, in the headspace of bottles at two timepoints (one day (cv. C) or two days (cv. B) after closing the bottles and when $\mathrm{O}_{2}$ concentration $<1 \%$ ). Data are mean $\pm \mathrm{SD}(n \leq 4)$ ).

\begin{tabular}{|c|c|c|c|c|c|c|}
\hline \multirow[t]{2}{*}{ Cultivar } & \multirow{2}{*}{$\frac{\text { Timepoint }}{\text { temperature }\left({ }^{\circ} \mathrm{C}\right):}$} & \multicolumn{5}{|c|}{ Ethylene Concentration (pmol mol-1) } \\
\hline & & $2.1 \pm 0.7$ & $5.2 \pm 0.6$ & $7.4 \pm 0.6$ & $9.9 \pm 0.5$ & $14.4 \pm 0.4$ \\
\hline \multirow{3}{*}{ cv. B } & After $49 \mathrm{~h}$ & n.a. ${ }^{x}$ & $347 \pm 68^{a}$ & $533 \pm 66^{\mathrm{ab}}$ & $875 \pm 16^{b}$ & $1420 \pm 7^{b}$ \\
\hline & When $\mathrm{O}_{2}<1 \%$ & n.a. ${ }^{x}$ & $407 \pm 62$ & $655 \pm 64$ & $1041 \pm 46$ & $1438 \pm 29$ \\
\hline & $t$-test & & ns & * & * & ns \\
\hline \multirow{4}{*}{ cv. C } & temperature $\left({ }^{\circ} \mathrm{C}\right)$ : & $1.7 \pm 0.9$ & $4.5 \pm 0.6$ & $7.5 \pm 0.8$ & $10.3 \pm 0.6$ & $14.5 \pm 0.4$ \\
\hline & After $25 \mathrm{~h}$ & $41 \pm 4^{\mathrm{a}}$ & $55 \pm 6^{a b}$ & $157 \pm 20^{a b c}$ & $314 \pm 17^{b c}$ & $527 \pm 78^{c}$ \\
\hline & When $\mathrm{O}_{2}<1 \%$ & $75 \pm 12$ & $91 \pm 6$ & $217 \pm 14$ & $367 \pm 18$ & $537 \pm 69$ \\
\hline & $t$-test & * & * & * & * & ns \\
\hline
\end{tabular}

$\mathrm{X}$ Only one observation available. ${ }^{\mathrm{a}, \mathrm{b}, \mathrm{c}}$ significant different groups according to the headspace ethylene concentration for the different temperatures (Dunn test adjusted $p$-value $<0.05$ ). * significant difference between first and second measurement, ns: nonsignificant difference between first and second measurement.

For $\mathrm{CB}$, when the $\mathrm{O}_{2}$ concentration was below $1 \%$, the ethylene concentration tended to increase compared to $49 \mathrm{~h}$ after closing the bottles. This increase was significant at 7 and $9^{\circ} \mathrm{C}$. For $\mathrm{CC}$, the ethylene concentration also tended to increase between $25 \mathrm{~h}$ after closing the bottles, compared to when the $\mathrm{O}_{2}$ concentration was below $1 \%$. The increase was significant for all temperatures, except for the highest temperature. However, the lack of a significant increase at the highest temperatures/temperature could be explained by the short time interval between the two measurements for both cultivars.

\subsection{Oxygen Consumption per Bottle}

The effect of time on the oxygen level in the bottle was modeled for each bottle separately using Equation (1). The values for the coefficients, the significance of the coefficients, and the fit of the model (adjusted $\mathrm{R}^{2}$ ) can be found in Supplementary Table S1. The models are based on 10 to 12 measurements. In all cases, the high adjusted $R^{2}(>0.99)$ indicates that almost all the variance can be explained by the model.

\subsection{The Combined Effect of Time and Temperature on the Oxygen Consumption}

In February, the first measurement after closing the bottles with Phalaenopsis plantlets took place after $\pm 20 \mathrm{~h}$. At that moment, the $\mathrm{O}_{2}$-concentration in the bottles stored at $32.6^{\circ} \mathrm{C}$ had already decreased below $2 \%$ and thus, the measurements on those bottles were excluded for building the general model. In the case of $\mathrm{CB}$, three out of four objects at the lowest temperature started leaking, and thus, the measurements for the objects at the lowest temperature were discarded. For the other experiments, the first measurements took place $\pm 12 \mathrm{~h}$ after closing the bottles to ensure enough measurements over a wider range of oxygen concentrations for the higher temperatures.

For the development of the general model, the measurements within $13 \mathrm{~h}$ after packaging were not taken into account because the adaptation processes to the modified headspace atmosphere might still influence the respiration rate. When the oxygen level dropped below 1.5\% (Phalaenopsis and CB) or below 1\% (CC), measurements were not taken into 
account because of the nearly anaerobic conditions inside the bottles, which could also influence the respiration.

The effect of the temperature was taken into account by using an Arrhenius equation as fixed effect on the coefficients of the quadratic model. Differences between the bottles were taken into account as random effects. The general models with the estimated coefficients are shown in Table 6. In Figure 1, the models are plotted against the measured values for the storage temperatures.

Table 6. Coefficients per set of plant materials for the general fixed-effects model shown as estimate \pm SE. Despite March being a replica of the experiment in February, coefficients tend to be different.

\begin{tabular}{ccccc}
\hline \multirow{2}{*}{$\begin{array}{c}\text { Model } \\
\text { Characteristics }\end{array}$} & \multicolumn{4}{c}{ Fixed Effects Models: Coefficients } \\
\cline { 2 - 5 } & \multicolumn{2}{c}{ Phalaenopsis } & \multicolumn{2}{c}{ Chrysanthemum } \\
\hline coefficients & $50.1 \pm 1.88^{* * *}$ & $48.4 \pm 1.51^{* * *}$ & cv. B & cv. C \\
\hline$\beta_{\mathrm{a}, 1}$ & $1.387 \times 10^{5} \pm 4.63 \times 10^{3 * * *}$ & $1.341 \times 10^{5} \pm 3.74 \times 10^{3 * * *}$ & $1.251 \times 10^{5} \pm 4.82 \times 10^{3 * * *}$ & $1.319 \times 10^{5} \pm 3.38 \times 10^{3 * * *}$ \\
\hline$\beta_{\mathrm{a}, 0}$ & $26.2 \pm 0.63^{* * *}$ & $25.4 \pm 0.62^{* * *}$ & $25.2 \pm 0.89^{* * *}$ & $27.0 \pm 0.60^{* * *}$ \\
\hline$\beta_{\mathrm{b}, 1}$ & $6.79 \times 10^{4} \pm 1.70 \times 10^{3 * * *}$ & $6.56 \times 10^{4} \pm 1.54 \times 10^{3 * * *}$ & $6.35 \times 10^{4} \pm 2.09 \times 10^{3 * * *}$ & $6.60 \times 10^{4} \pm 1.37 \times 10^{3 * * *}$ \\
\hline$\beta_{\mathrm{b}, 0}$ & $9.45 \pm 0.07^{* * *}$ & $9.85 \pm 0.04 * * *$ & $8.66 \pm 0.06^{* * *}$ & $8.86 \pm 0.10^{* * *}$ \\
\hline $\mathrm{c}$ & & observation and group counts & 153 \\
\hline $\mathrm{N}^{\circ}$ obs. & 136 & 134 & 94 \\
\hline $\mathrm{N}^{\circ}$ groups & 19 & 19 & 16 & 20 \\
\hline
\end{tabular}

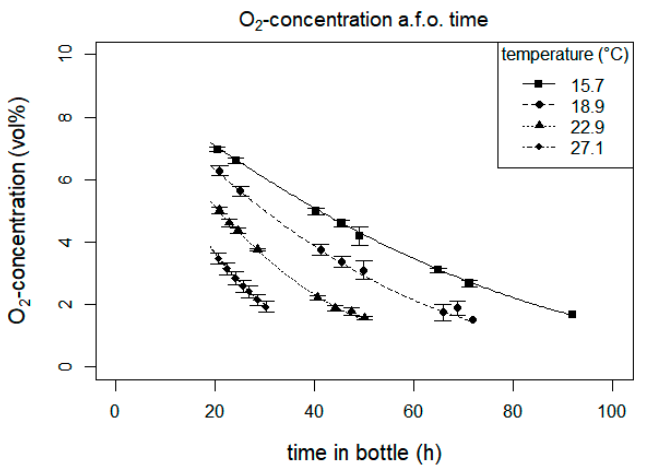

(a)

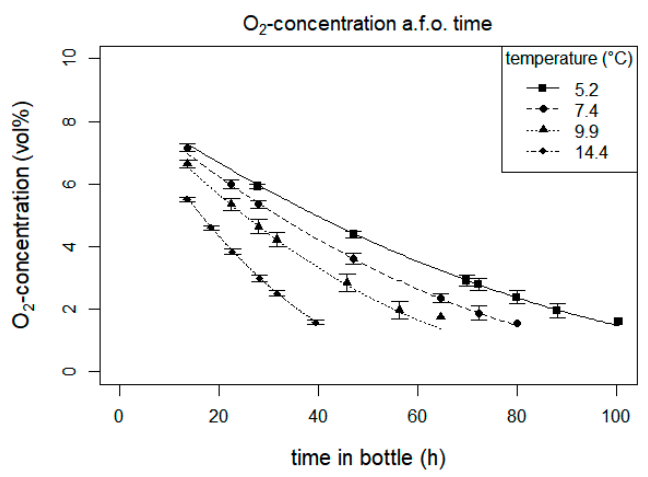

(c)

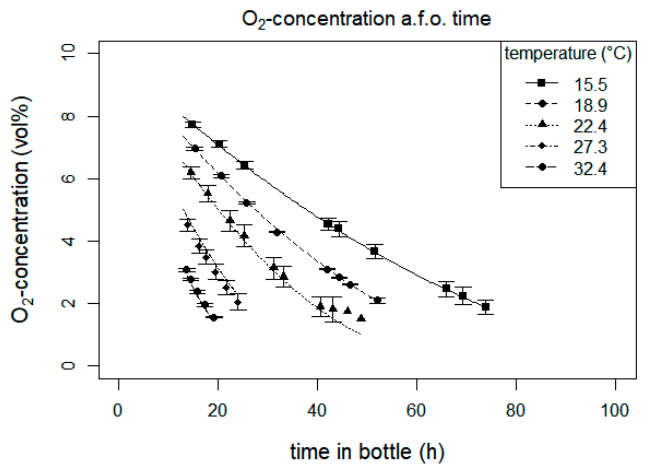

(b)

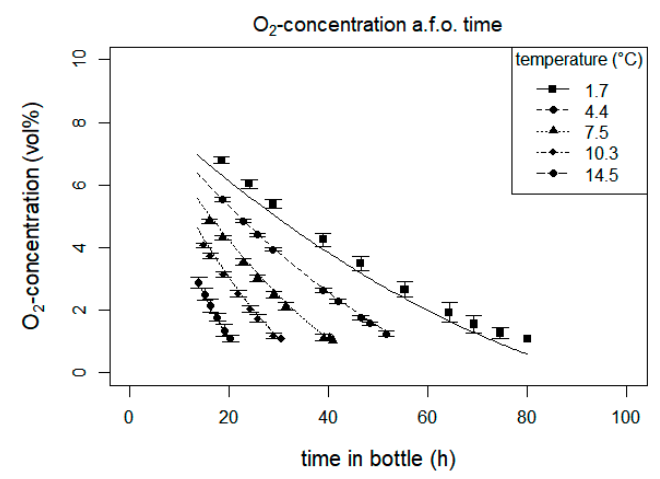

(d)

Figure 1. $\mathrm{O}_{2}$ concentration as a function of time for the different temperatures. Lines: fitted values per storage temperature based on the fixed effects; dots: mean of measured values; whiskers: standard deviation of measured values. (a) Phalaenopsis February; (b) Phalaenopsis March; (c) Chrysanthemum cv. B; (d) Chrysanthemum cv. C. 


\subsection{Model Evaluation}

In all cases, the modeled $\mathrm{O}_{2}$ concentrations approach the observed $\mathrm{O}_{2}$ concentrations quite well according to Figure 1. The predicted values for each observation are plotted as a function of the respective observed values in Figure 2. For values close to the full line, the observed value equals the predicted value.

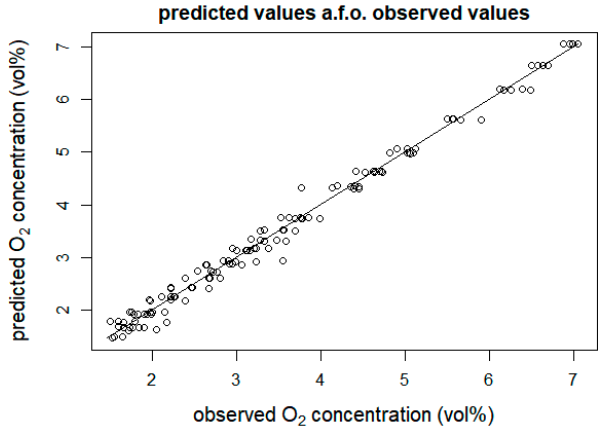

(a)

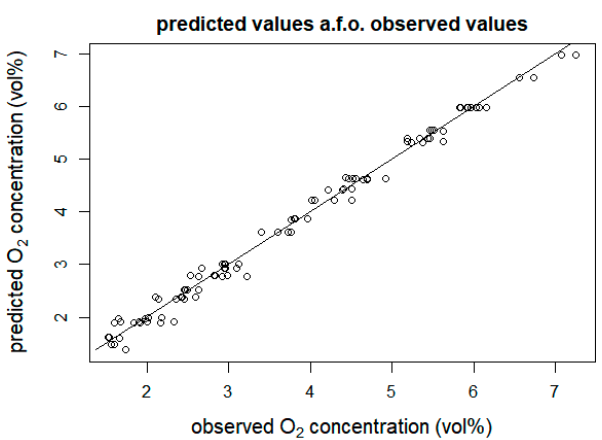

(c)

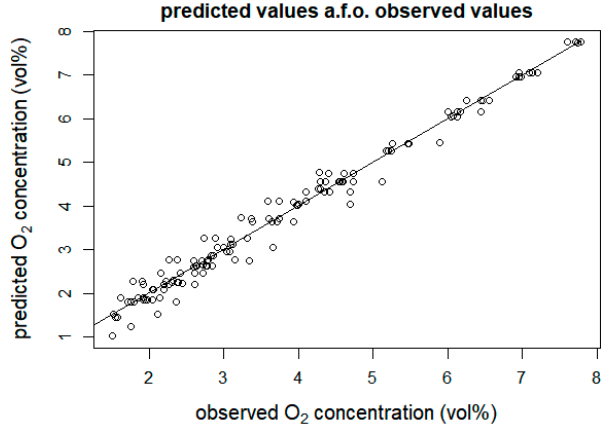

(b)

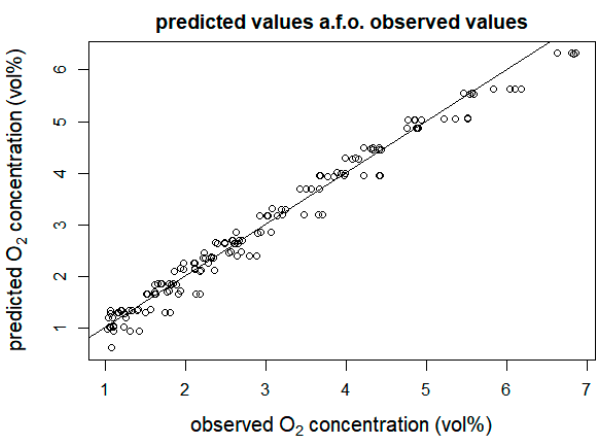

(d)

Figure 2. Predicted $\mathrm{O}_{2}$ concentration (based on fixed effects only) as a function of the observed $\mathrm{O}_{2}$ concentration (dots). (a) Phalaenopsis February; (b) Phalaenopsis March; (c) Chrysanthemum cv. B; (d) Chrysanthemum cv. C.

\subsection{Respiration Rates}

The OCR's were calculated from the models and plotted as a function of $\mathrm{O}_{2}$ concentration for the different storage temperatures (Figure 3). The figure shows that the effect of the $\mathrm{O}_{2}$ concentration is more pronounced at higher temperatures. The effect of decreasing the $\mathrm{O}_{2}$ concentration was larger in the lower $\mathrm{O}_{2}$ concentration range. Despite the use of the same Phalaenopsis clone in February and in March, the OCR seemed to be higher in March for (approximately) the same $\mathrm{O}_{2}$ concentration and temperature.

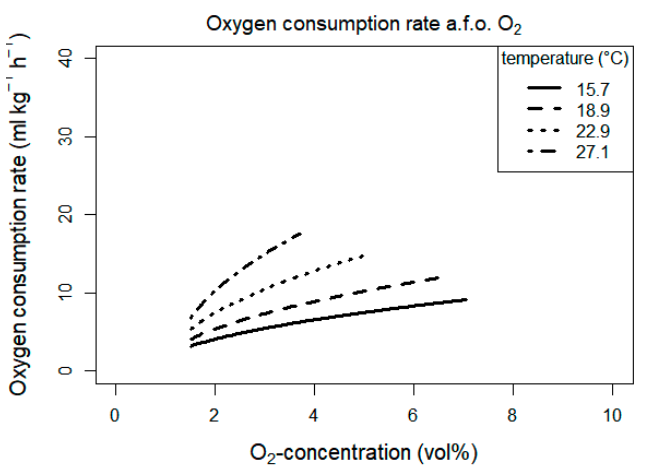

(a)

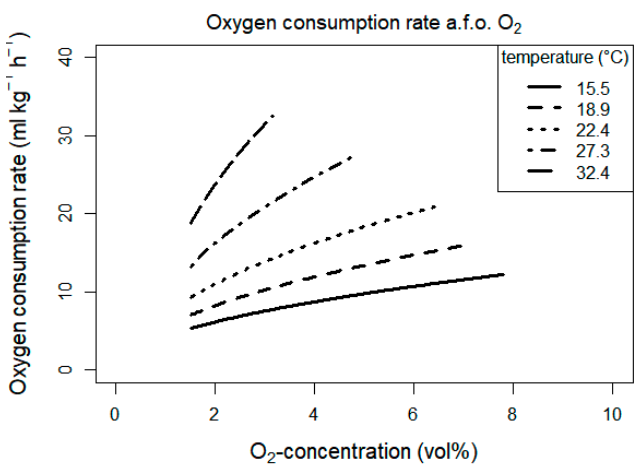

(b)

Figure 3. Cont. 


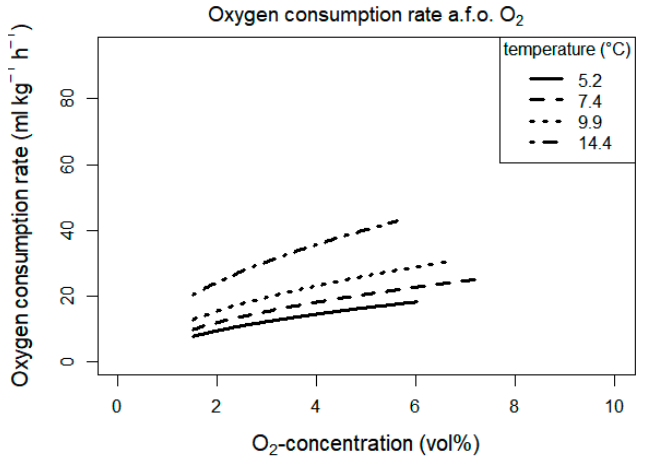

(c)

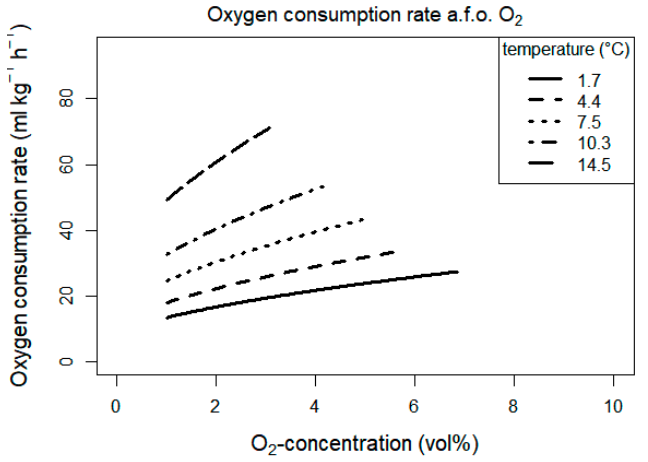

(d)

Figure 3. Oxygen consumption rate as a function of $\mathrm{O}_{2}$ concentration for the different temperatures for (a) Phalaenopsis February; (b) Phalaenopsis March; (c) Chrysanthemum cv. B; (d) Chrysanthemum cv. C.

The $O C R^{\prime} \mathrm{s}$ were calculated from the models and plotted as a function of temperature for five different $\mathrm{O}_{2}$ concentrations (Figure 4). The effect of the temperature is more pronounced at a higher $\mathrm{O}_{2}$ concentration

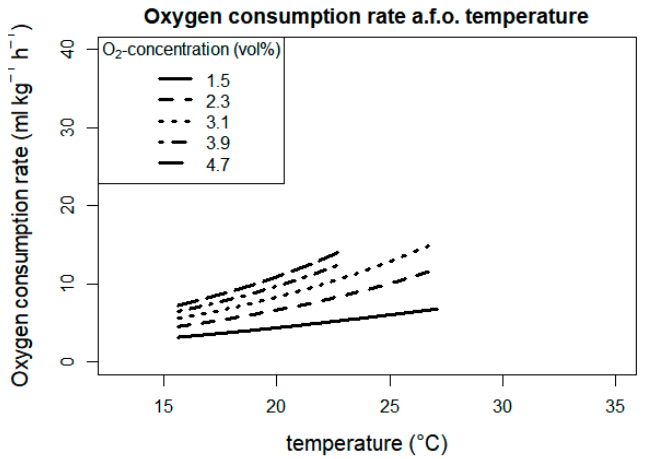

(a)

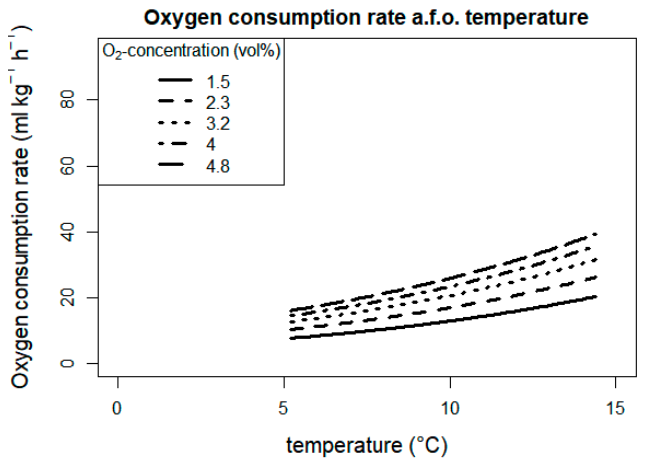

(c)

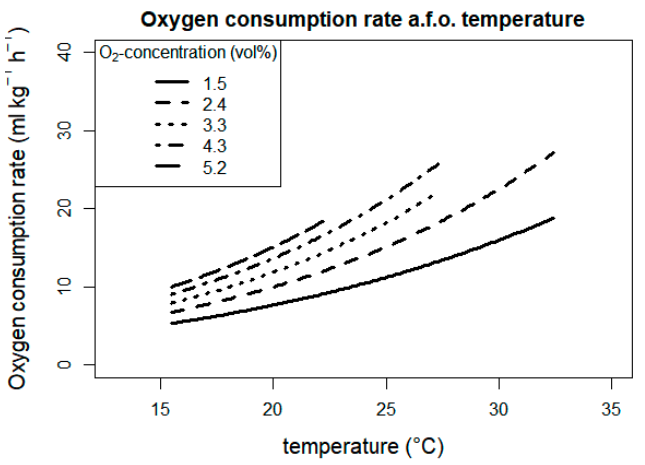

(b)

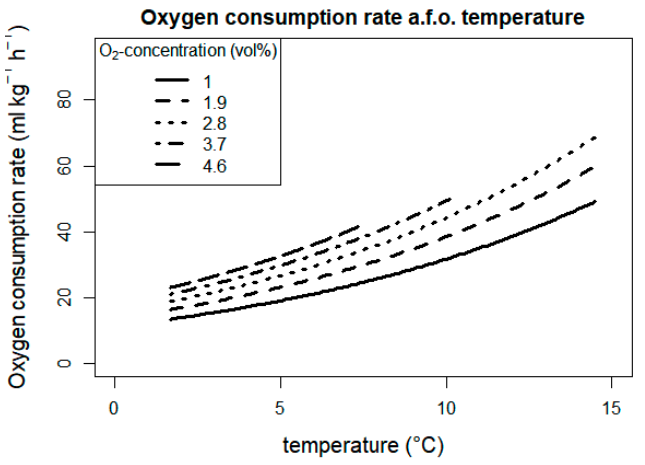

(d)

Figure 4. Oxygen consumption rate as a function of five different $\mathrm{O}_{2}$ concentrations for (a) Phalaenopsis in February, (b) Phalaenopsis in March, (c) Chrysanthemum cv. B; (d) Chrysanthemum cv. C.

\section{Discussion}

For the development of effective EMA packages for ornamental plant materials, it is of utmost importance to know the respiration rate of the produce of interest [15]. To our knowledge, the oxygen consumption rate of both Phalaenopsis plantlets and Chrysanthemum cuttings (and by extension most ornamental starting materials) has never been modeled as a function of $\mathrm{O}_{2}$ concentration and temperature before. However, for minimally processed produce in the agro-food sector, there are models available. In this work, a combination of a quadratic model type and an Arrhenius type of model $[12,17]$ to determine the res- 
piration rate, was used with some modifications to enable an estimation of the model coefficients in one step, rather than two succeeding steps. The model coefficients depended on the plant species. In the case of Phalaenopsis, the different residence times in the last subculture also tended to influence the model coefficients, resulting in different respiration rates. For example: at $25{ }^{\circ} \mathrm{C}$ and $3 \% \mathrm{O}_{2}$, the plantlets from February had a theoretical OCR of $12.56 \mathrm{~mL} \mathrm{~kg}^{-1 *} \mathrm{~h}^{-1}$ while the plantlets from March had a theoretical OCR of $17.22 \mathrm{~mL} \mathrm{~kg}^{-1} \mathrm{~h}^{-1}$. A quadratic function was fitted to the measured oxygen concentration as a function of the time for the individual bottles, yielding a $R^{2}$ adj $>99 \%$ in all studied cases during these experiments (Supplementary Table S1). A similar good fit $\left(\mathrm{R}^{2}>99 \%\right)$ of a quadratic equation to the measured oxygen concentration as a function of the time was found for tomato by Gong and Corey [17] but fruit tissue is very distinct from the root, stem, and leaf tissue of Phalaenopsis plantlets and Chrysanthemum cuttings. However, for leafy vegetables and root vegetables such as trimmed Brussels sprouts, shredded spinach, shredded chicory endives, shredded iceberg lettuce, and grated carrots, the same good fit $\left(\mathrm{R}^{2}>99 \%\right)$ of a quadratic model to the experimental data has been found [12]. Jacxsens et al. [12] calculated the theoretical respiration rate for the mentioned leafy and root vegetables at $3 \% \mathrm{O}_{2}$ and temperatures ranging from $2{ }^{\circ} \mathrm{C}$ to $15^{\circ} \mathrm{C}$. At $15^{\circ} \mathrm{C}$, Phalaenopsis plantlets had a rather low OCR $\left(5.16 \mathrm{~mL} \mathrm{~kg}^{-1} \mathrm{~h}^{-1}\right.$ and $7.23 \mathrm{~mL} \mathrm{~kg}^{-1} \mathrm{~h}^{-1}$ for plantlets from February and March respectively) compared to the OCR of the mentioned vegetables (ranging from $7.15 \mathrm{~mL} \mathrm{~kg}^{-1} \mathrm{~h}^{-1}$ for chicory endive heads to $25.07 \mathrm{~mL} \mathrm{~kg}^{-1} \mathrm{~h}^{-1}$ for mungbean sprouts). This is in strong contrast to Chrysanthemum cuttings which had in comparison a high OCR in the case of $C B\left(32.28 \mathrm{~mL} \mathrm{~kg}^{-1} \mathrm{~h}^{-1}\right)$ or a very high OCR in the case of $\mathrm{CC}\left(74.07 \mathrm{~mL} \mathrm{~kg}^{-1} \mathrm{~h}^{-1}\right)$ at $3 \% \mathrm{O}_{2}$ and $15^{\circ} \mathrm{C}$.

A positive correlation between $O C R$ and $\mathrm{O}_{2}$ concentration was found for all the studied plant materials and this positive relationship was more pronounced at higher temperatures, which complies with similar studies on fresh-cut rocket lettuce [23] and fresh-cut bell peppers [24]. In cut carnation flowers, hypoxia $\left(\mathrm{O}_{2}\right.$ concentration $\left.=5.01 \mathrm{kPa}\right)$ was found to halve the speed of carbon dioxide production and delay senescence, which also confirms our observation that the respiration rate slows down when lowering the $\mathrm{O}_{2}$ concentration. Geigenberger [25] proposed the existence of an oxygen-sensing system in plants that restricts the metabolism when the internal $\mathrm{O}_{2}$ concentration decreases. This oxygen-sensing system was later reviewed by Bailey-Seres and Chang [26]. The existence of such a sensory system could explain the reduction of $O C R$ at low $\mathrm{O}_{2}$ concentrations.

Next to $\mathrm{O}_{2}$ concentration, other parameters are mentioned in the literature to be correlated with the respiration rate. For example, Li et al. [27] found a positive correlation between the respiration rate and $\mathrm{CO}_{2}$ concentration for growing tomato plants. In contrast, Gonzàlez-Meler [28] found an inhibitory effect of elevated $\mathrm{CO}_{2}$ on plant respiration, probably due to inhibition of Cytochrome c oxidase. Hertog [29] found inhibition of the OCR by $\mathrm{CO}_{2}$ concentration for apple, chicory, and tomato fruits. However, the experimental setup of this study did not allow to distinguish the $\mathrm{CO}_{2}$ concentration effects on the OCR since a decrease in $\mathrm{O}_{2}$ concentration is always accompanied by a decrease in $\mathrm{CO}_{2}$ concentration and an accumulation of ethylene in a closed system.

The accumulated ethylene concentration depended in this research on the studied species and cultivar. In the case of Chrysanthemum cuttings, the ethylene concentration was positively correlated with the storage temperature, which was also reported for poinsettia cuttings [30]. The influence of ethylene on the respiration rate could not be deduced from this research.

Phalaenopsis roots contained higher soluble carbohydrate contents than the shoots. These findings are in accordance with the findings of Hou, Miller, and Chang [6] who studied the effect of dark shipping on mature Phalaenopsis plants. The lower hexose content of the leaves in February compared to March, can be explained by the longer residence time of the plantlets on the growth medium and the uptake and metabolism of the plantlets. Soluble carbohydrate quantification on the starting materials indicated a positive correlation between the respiration rate of Phalaenopsis and the initial hexose levels 
of the leaves. Azcón-Bieto, Lambers and Day [31] found an enhanced OCR in spinach from $0.51 \mu \mathrm{mol} \mathrm{m}{ }^{-2} \mathrm{~s}^{-1}$ after a dark period to $0.80 \mu \mathrm{mol} \mathrm{m}^{-2} \mathrm{~s}^{-1}$ after $5 \mathrm{~h}$ to $7 \mathrm{~h}$ light and an increased OCR from $0.51 \mu \mathrm{mol} \mathrm{m}{ }^{-2} \mathrm{~s}^{-1}$ after a dark period to $1.32 \mu \mathrm{mol} \mathrm{m} \mathrm{m}^{-2} \mathrm{~s}^{-1}$ after $6 \mathrm{~h}$ light for wheat leaves. During the light period, carbohydrates are synthesized by photosynthesis and thus, higher carbohydrate levels can be expected after periods of light. For Phalaenopsis plantlets, the correlation between soluble carbohydrate content and respiration rate needs further investigation. The results of this research indicate a correlation between the cultivar and the OCR for Chrysanthemum and in their capacity to accumulate carbohydrates. Higher carbohydrate content can induce higher respiration rates. Indeed, when looking at the results, $\mathrm{CC}$ has a higher overall respiration rate and has generally a higher hexose content $\left(1.70 \mathrm{mg} \mathrm{g}^{-1}\right.$ and $1.62 \mathrm{mg} \mathrm{g}^{-1} \mathrm{FW}$ in leaves and stems respectively) compared to the lower respiring $\mathrm{CB}\left(0.80 \mathrm{mg} \mathrm{g}^{-1}\right.$ and $0.79 \mathrm{mg} \mathrm{g}^{-1} \mathrm{FW}$ in leaves and stems respectively). The disaccharide sucrose, however, is more abundant in the tissue of the slower respiring CB.

As stated above, the positive effect of a low temperature and modified atmosphere on the shelf life of minimally processed produce was proven in several cases. For ornamentals, reports are rather scarce and focused on cut flowers. Modified atmosphere packaging with oxygen scavengers was found to successfully enhance the vase life of cut gladiolus spikes when stored at high temperatures $\left(15^{\circ} \mathrm{C}\right.$ to $\left.20^{\circ} \mathrm{C}\right)$ without any preliminary study of the respiration rate [32]. Another study showed a positive effect of modified atmosphere packaging on the vase life of tulip flowers in cold storage [33]. Despite proof of the value of modified atmosphere packaging for gladiolus (under certain conditions) and tulip flowers, one could argue whether the used packaging in both studies is the most optimal for these flowers since only a few different packages were tested. Determination of the respiration rate as in our study might allow for further optimization of modified atmosphere packaging for these ornamentals amongst others.

\section{Conclusions}

The respiration rate of both Phalaenopsis and Chrysanthemum is higher at a higher temperature and is also positively correlated with the oxygen concentration. The oxygen concentration will have a more pronounced effect on the respiration rate at higher temperatures. Based on the data, four models with the same structure but different coefficients for Phalaenopsis plantlets in February (8) and March (9), Chrysanthemum cv. B (10) and Chrysanthemum cv. C (11) are proposed:

$$
\begin{gathered}
O C R=V /(100 \times m) \sqrt{\exp \left[26.2-6.79 \times 10^{4} /(R \times T)\right]^{2}-4 \exp \left[50.1-1.387 \times 10^{5} /(R \times T)\right]\left(9.45-\left[O_{2}\right]\right)} \\
O C R=V /(100 \times m) \sqrt{\exp \left[25.4-6.56 \times 10^{4} /(R \times T)\right]^{2}-4 \exp \left[48.4-1.341 \times 10^{5} /(R \times T)\right]\left(9.85-\left[O_{2}\right]\right)} \\
O C R=V /(100 \times m) \sqrt{\exp \left[25.2-6.35 \times 10^{4} /(R \times T)\right]^{2}-4 \exp \left[46.1-1.251 \times 10^{5} /(R \times T)\right]\left(8.66-\left[O_{2}\right]\right)} \\
O C R=V /(100 \times m) \sqrt{\exp \left[27.0-6.60 \times 10^{4} /(R \times T)\right]^{2}-4 \exp \left[50.3-1.319 \times 10^{5} /(R \times T)\right]\left(8.86-\left[O_{2}\right]\right)}
\end{gathered}
$$

With the proposed models, one can easily estimate the respiration rate under a given $\mathrm{O}_{2}$ concentration and temperature and the model can thus be used to estimate the $\mathrm{O}_{2}$ consumption for a dynamic temperature profile. Model coefficients should be estimated for each plant species or even cultivar. Next to species-specific differences, there are some strong indications that the photosynthates or reserve availability of the plant materials might play an important role in the actual respiration rate during dark storage.

Supplementary Materials: The following Supplementary Materials are available at https:/ / www. mdpi.com/2073-4395/11/2/237/s1: Figure S1: logged temperatures during commercial transport, Table S1: Coefficients for the quadratic function describing the evolution of the $\mathrm{O}_{2}$ concentration in function of time. 
Author Contributions: Conceptualization, A.C. and L.V.d.V.; methodology, L.V.d.V., A.V., F.D. and P.R.; formal analysis, L.V.d.V.; investigation, L.V.d.V.; resources, A.C.; data curation, L.V.d.V.; writing—original draft preparation, L.V.d.V.; writing—review and editing, A.V., F.D., M.-C.V.L., A.C. and P.R.; visualization, L.V.d.V.; project administration, L.V.d.V.; funding acquisition, A.C., F.D. and M.-C.V.L. All authors have read and agreed to the published version of the manuscript.

Funding: This research was funded by Agentschap Innoveren en Ondernemen (VLAIO), grant number 170835 .

Institutional Review Board Statement: Not applicable.

Informed Consent Statement: Not applicable.

Data Availability Statement: Data will be available without any reservations by the authors to qualified researchers.

Acknowledgments: A special word of thanks goes to the PCS Ornamental Plant Research, Belgium, and Microflor, Belgium for providing the plant materials. The authors want to thank the staff of the laboratory of orticulture and the staff of the laboratory of food microbiology and food preservation for the technical support. A final word of gratitude goes to FLAMES (Flanders' training network for methodology and statistics) for support with the development of the model.

Conflicts of Interest: The authors declare no conflict of interest. The funders had no role in the design of the study; in the collection, analyses, or interpretation of data; in the writing of the manuscript, or in the decision to publish the results.

$\begin{array}{ll}\text { Abbreviations } \\ \text { CA/CB/CC } & \text { Chrysanthemum cuttings cv. A/B/C } \\ \text { EMA }(\mathrm{P}) & \text { Equilibrium modified atmosphere (packaging) } \\ \text { FID } & \text { flame ionization detector } \\ \text { GC } & \text { gas chromatograph } \\ \text { OCR } & \text { oxygen consumption rate } \\ \text { TCD } & \text { thermal conductivity detector }\end{array}$

\section{References}

1. Govaerts, R. World Checklist of Orchidaceae. Available online: https://wcsp.science.kew.org/namedetail.do?name_id=151129 (accessed on 4 February 2020).

2. Griesbach, R. Development of Phalaenopsis orchids for the mass-market. Trends New Crop. Uses 2002, 2000, 458-465.

3. Floraholland Annual Report. 2019. Available online: https://jaarverslag2019.royalfloraholland.com/?_ga=2.12156404.111597046 8.1598451513-1799573506.1594389680\#/feiten-en-cijfers/kamerplanten?_k=aylu3c (accessed on 6 August 2020).

4. Anderson, N.O. Flower Breeding and Genetics; Anderson, N.O., Ed.; Springer: Dordrecht, The Netherlands, 2006; pp. 389-438. ISBN 9781402065699.

5. Westra, E.H.; Boerrigter, H.A.M.; Paillart, M. Research voor co-modaal sierteelttransport; Wageningen. Food Biobased Res. 2011, $1213,1-52$.

6. Hou, J.Y.; Miller, W.B.; Chang, Y.C.A. Effects of simulated dark shipping on the carbohydrate status and post-shipping performance of Phalaenopsis. J. Am. Soc. Hortic. Sci. 2011, 136, 364-371. [CrossRef]

7. Muniz, A.C.C.; Galati, V.C.; Marques, K.M.; Mattiuz, C.F.M.; Mattiuz, B.-H. Postharvest quality of red gerberas depending on the storage temperature. Ciência Rural 2016, 46, 1945-1951. [CrossRef]

8. Devecchi, M.; Van Meeteren, U.; De Wild, H.; Woltering, E. Effects of low $\mathrm{O}_{2}$ on cut rose flowers at suboptimal temperature. Acta Hortic. 2003, 628, 855-861. [CrossRef]

9. Su, V.; Hsu, B.D.; Chen, W.H. The photosynthetic activities of bare rooted Phalaenopsis during storage. Sci. Hortic. 2001, 87, 311-318. [CrossRef]

10. Druege, U.; Zerche, S.; Kadner, R.; Ernst, M. Relation between nitrogen status carbohydrate distribution and subsequent rooting of chrysanthemum cuttings as affected by pre-harvest nitrogen supply and cold-storage. Ann. Bot. 2000, 85, 687-701. [CrossRef]

11. Wilson, M.D.; Stanley, R.A.; Eyles, A.; Ross, T. Innovative processes and technologies for modified atmosphere packaging of fresh and fresh-cut fruits and vegetables. Crit. Rev. Food Sci. Nutr. 2017, 59, 411-422. [CrossRef]

12. Jacxsens, L.; Devlieghere, F.; Debevere, J. Validation of a Systematic Approach to Design Equilibrium Modified Atmosphere Packages for Fresh-Cut Produce. LWT Food Sci. Technol. 1999, 32, 425-432. [CrossRef]

13. Briassoulis, D.; Mistriotis, A.; Giannoulis, A.; Giannopoulos, D. Optimized PLA-based EMAP systems for horticultural produce designed to regulate the targeted in-package atmosphere. Ind. Crops Prod. 2013, 48, 68-80. [CrossRef] 
14. Fonseca, S.C.; Oliveira, F.A.R.; Brecht, J.K. Modelling respiration rate of fresh fruits and vegetables for modified atmosphere packages: A review. J. Food Eng. 2002, 52, 99-119. [CrossRef]

15. Beaudry, R.M. Responses of Horticultural Commodities to Low Oxygen: Modified Atmosphere Packaging. Horttechnology 2000, 10, 491-500. [CrossRef]

16. Boehringer Mannheim. Methods of Biochemical Analysis and Food Analysis Using Test-Combinations; Boehringer Mannheim GmbH: Mannheim, West-Germany, 1989; p. 142.

17. Gong, S.; Corey, K.A. Predicting steady-state oxygen concentrations in modified-atmosphere packages of tomatoes. J. Am. Soc. Hortic. Sci. 1994, 119, 546-550. [CrossRef]

18. Jacxsens, L.; Devlieghere, F.; De Rudder, T.; Debevere, J. Designing Equilibrium Modified Atmosphere Packages for Fresh-cut Vegetables Subjected to Changes in Temperature. Food Sci. Technol. 2000, 33, 178-187.

19. R Core Team. R Foundation for Statistical Computing R: A Language and Environment for Statistical Computing; R Core Team: Vienna, Austria, 2019.

20. Pinheiro, J.; Bates, D.; DebRoy, S.; Sarkar, D. R-Core Team Nlme: Linear and Nonlinear Mixed Effects Models. 2020. Available online: https:/ / cran.r-project.org/web/packages/nlme/index.html (accessed on 10 December 2020).

21. Fox, J.; Weisberg, S.; Price, B. carData: Companion to Applied Regression Data Sets. R Package Version 3.0-2. 2018. Available online: https:/ / cran.r-project.org/web/packages/carData/index.html (accessed on 22 May 2020).

22. Fox, J.; Weisberg, S. An \{R\} Companion to Applied Regression, 3rd ed.; Sage: New York, NY, USA, 2019; Available online: https: // socialsciences.mcmaster.ca/jfox/Books/Companion/ (accessed on 17 May 2020).

23. Pereira, M.J.; Amaro, A.L.; Pintado, M.; Poças, M.F. Modeling the effect of oxygen pressure and temperature on respiration rate of ready-to-eat rocket leaves. A probabilistic study of the Michaelis-Menten model. Postharvest Biol. Technol. 2017, 131, 1-9. [CrossRef]

24. Conesa, A.; Verlinden, B.E.; Artés-Hernández, F.; Nicolaï, B.; Artés, F. Respiration rates of fresh-cut bell peppers under supertamospheric and low oxygen with or without high carbon dioxide. Postharvest Biol. Technol. 2007, 45, 81-88. [CrossRef]

25. Geigenberger, P. Response of plant metabolism to too little oxygen. Curr. Opin. Plant Biol. 2003, 6, 247-256. [CrossRef]

26. Bailey-Serres, J.; Chang, R. Sensing and signalling in response to oxygen deprivation in plants and other organisms. Ann. Bot. 2005, 96, 507-518. [CrossRef]

27. Li, X.; Zhang, G.; Sun, B.; Zhang, S.; Zhang, Y.; Liao, Y.; Zhou, Y.; Xia, X.; Shi, K.; Yu, J. Stimulated leaf dark respiration in tomato in an elevated carbon dioxide atmosphere. Sci. Rep. 2013, 3, 2-9. [CrossRef]

28. Gonzàlez-Meler, M.A.; Ribas-Carbó, M.; Siedow, J.N.; Drake, B.G. Direct inhibition of plant mitochondrial respiration by elevated $\mathrm{CO}_{2}$. Plant Physiol. 1996, 112, 1349-1355. [CrossRef]

29. Hertog, M.L.A.T.M.; Peppelenbos, H.W.; Evelo, R.G.; Tijskens, L.M.M. A dynamic and generic model of gas exchange of respiring produce: The effects of oxygen, carbon dioxide and temperature. Postharvest Biol. Technol. 1998, 14, 335-349. [CrossRef]

30. Enfield, A. Influence of the Postharvest Environment on the Storage Potential and Propagation Performance of Unrooted Cuttings of Herbaceous Ornamentals. Ph.D. Thesis, Clemson University, Clemson, SC, USA, August 2011.

31. Azcón-Bieto, J.; Lambers, H.; Day, D.A. Effect of Photosynthesis and Carbohydrate Status on Respiratory Rates and the Involvement of the Alternative Pathway in Leaf Respiration. Plant Physiol. 1983, 72, 598-603. [CrossRef] [PubMed]

32. Shimizu-Yumoto, H.; Ichimura, K. Effect of storage in packaging with oxygen absorbers on the quality of cut gladiolus "Princess Summer Yellow" spikes. Postharvest Biol. Technol. 2016, 111, 191-196. [CrossRef]

33. Aros, D.; Orellana, K.; Escalona, V. Modified atmosphere packaging as a method to extend postharvest life of tulip flowers. New Zeal. J. Crop Hortic. Sci. 2017, 45, 202-215. [CrossRef] 